\title{
Las articulaciones globales del campo colombiano: FENSUAGRO, el Coordinador Nacional Agrario y la Vía Campesina
}

\author{
The global articulations of the colombian countryside: \\ FENSUAGRO, the National Agrarian Coordinator and La Vía \\ Campesina
}

\begin{abstract}
As articulações globais do campo colombiano: FENSUAGRO, o Coordenador Nacional Agrário e a Via Campesina
\end{abstract}

Carolina Cepeda Másmela* , Julián Muñoz Londoño**

\section{RESUMEN}

Este trabajo buscó comprender los procesos de articulación glo-

Palabras clave:

bal que llevan a cabo los movimientos campesinos colombianos al trabajar articuladamente sus luchas una vez enmarcadas dentro del accionar global de La Vía Campesina (LVC). Las relaciones entre los movimientos locales y los globales serán vistas desde una lógica integral de la acción colectiva, que aborda tanto las identidades del movimiento campesino como sus estrategias y formas de organización. Se recurre a herramientas teóricas tanto de los movimientos sociales como de los marcos de acción colectiva. En ese equilibrio, es necesaria una lectura crítica del esceacción colectiva, movimientos campesinos colombianos, La Vía Campesina, movimientos sociales globales, identidad campesina. nario internacional (neoliberal y moderno/colonial) ante el que responden los nuevos procesos de movilización campesina. Mediante una revisión documental acerca del accionar de los mayores movimientos campesinos colombianos parte de LVC, y un trabajo de campo se concluye que las experiencias de creación de plataformas políticas, movilización, organización y formación político-técnica son muestras de los nuevos campos de acción

* Doctora en Ciencia Política de la Universidad de los Andes. Profesora asistente del Departamento de Relaciones Internacionales de la Pontificia Universidad Javeriana, Bogotá, Colombia. E-mail: ycepeda@javeriana.edu.co

** Politólogo e internacionalista de la Pontificia Universidad Javeriana. Bogotá, Colombia.E-mail: Julian.ml.1908@gmail.com 
conjunta campesina en Colombia, América Latina y el mundo en resistencia a un sistema global neoliberal.

\begin{abstract}
This work sought to understand the global articulation processes that Colombian peasant movements carry out as they work to articulate their struggles once framed within the worldwide movement La Via Campesina (LVC). The relations between local and global trends will be seen from an integral logic of collective action, which addresses the peasant movement's identities and its strategies and forms of organization. Theoretical tools from both social movements and collective action frameworks are used. In this balance, a critical reading of the international scenario (neoliberal and modern/colonial) is necessary, to which the new peasant mobilization processes respond. By analyzing Colombia's largest peasant movements, part of LVC, we conclude that political platforms, mobilization, organization, and politicaltechnical training are samples of the new joint peasant action in Colombia, Latin America, the world in resistance to a neoliberal global system.
\end{abstract}

\section{RESUMO}

Este trabalho procurou compreender os processos de articulação global executados pelos movimentos camponeses colombianos ao trabalharem juntos em suas lutas, uma vez enquadradas na ação global da Via Campesina (VC). As relações entre os movimentos locais e globais serão vistas a partir de uma lógica integral de ação coletiva, que aborda tanto as identidades do movimento camponês quanto suas estratégias e formas de organização. São utilizadas ferramentas teóricas tanto dos movimentos sociais como das estruturas de ação coletiva. Neste equilíbrio, é necessária uma leitura crítica do cenário internacional (neoliberal e moderno/colonial), ao qual os novos processos de mobilização camponesa respondem. Através de uma revisão documental das ações dos maiores movimentos camponeses colombianos, parte da VC, e um estudo de campo, conclui-se que as experiências de criação de plataformas políticas, mobilização, organização e formação político-técnica são amostras dos novos campos de ação conjunta dos camponeses na Colômbia, América Latina e no mundo em resistência a um sistema global neoliberal.
Keywords: collective action, Colombian peasant movements, La Via Campesina, global social movements, peasant identity.

Palavras-chave: ação coletiva, movimentos camponeses colombianos, Via Campesina, movimentos sociais globais, identidade camponesa. 


\section{Introducción}

Desde la década de 1990 los procesos de transnacionalización de la economía, la producción y los flujos de personas e información se intensificaron. Surgieron nuevas oportunidades para una movilización social (Tarrow, 2007), que desde décadas atrás ya se configuraba con procesos de organización a nivel local, nacional, regional e incluso global (Tilly, 2010), pero que en el contexto de la globalización neoliberal encuentra nuevos argumentos e incentivos para fortalecer su lucha. De allí que sea válido entender las dinámicas políticas a partir de la propuesta que hace Robert Cox (1981) respecto de estructuras históricas moldeadas por la interacción entre órdenes mundiales, formas de Estado y fuerzas sociales donde, además, es posible entender la incidencia de distintos agentes sociales en la política internacional.

Un ejemplo de esas movilizaciones se encuentra en el campesinado, que ha padecido exclusiones históricas que se han profundizado por la implementación de políticas neoliberales de apertura económica y comercial erigidas como hegemónicas (Cox, 1981; Gill, 2008) y reforzadas en América Latina durante las últimas décadas. Dentro de este sector, la Vía Campesina (en adelante LVC) aparece como un actor clave, que puede definirse como un movimiento social global de campesinos para campesinos, producto de una lucha constante que adquiere matices locales y globales, respondiendo a los cambios que se han dado en la política internacional desde la década de 1990.

LVC nació en 1992 y desde entonces ha promovido una identificación regional y global del campesinado, contando con procesos locales y nacionales importantes, como se ilustra en el caso de Colombia. Su repertorio comprende estrategias como la formación técnico-política, el seguimiento de políticas de transformación, producción y gestión del conocimiento, y la proyección estratégica de los movimientos locales.

Este trabajo sostiene que LVC es central para entender los procesos de movilización campesina articulados globalmente, en los que interactúa con distintos actores como Estados, organizaciones internacionales y otros movimientos sociales. Una de sus mayores contribuciones se ha dado en el terreno de la construcción de nuevos rumbos a la hora de pensar y repensar "lo campesino", tanto desde su heterogeneidad 
identitaria como desde su capacidad de agencia política en respuesta a las políticas neoliberales. Gran parte del campesinado ha reorientado sus luchas en lo local, lo regional y lo global, tras la búsqueda de un equilibrio entre una diversidad identitaria y una unidad organizativa. Esta articulación supone unos vínculos de reconocimiento y agenciamiento político que, a su vez, permiten poner en diálogo los procesos de construcción subjetiva de "lo campesino" con los procesos de participación, reconfiguración política y transformación de realidades; todo esto dentro de unos marcos de acción colectiva flexibles que se nutren de la diversidad y de los aprendizajes colectivos-organizativos y de estrategias de movilización.

De allí la importancia de conocer con más profundidad los procesos que se dan en las organizaciones locales que hacen parte de LVC. Así, este artículo se centra en dos experiencias colombianas que abanderan el encuentro de movimientos campesinos nacionales con procesos globales como LVC: la Federación Nacional Sindical Unitaria Agropecuaria, Fensuagro, y el Coordinador Nacional Agrario, CNA. Ambas organizaciones han construido distintos vínculos con LVC en un proceso que ha sido poco explorado por las ciencias sociales y que cobra especial relevancia si se tiene en cuenta el Acuerdo de Paz firmado por el gobierno de Juan Manuel Santos y la exguerrilla de las Fuerzas Armadas Revolucionarias de Colombia, FARC, en 2016, que abrió una ventana de oportunidad para la participación política de sectores tradicionalmente excluidos, pese a los riesgos para los líderes sociales que persisten en el país.

Este trabajo se centró en el análisis de dos mecanismos cruciales para el fortalecimiento solidario y organizativo de las resistencias contra políticas neoliberales y órdenes globales injustos: las identidades colectivas y los repertorios de movilización social. Ambos aspectos son fundamentales para entender los rumbos de la subjetivación campesina diversa a partir de las mismas formas de participación, formación y organización política. Su análisis fue posible a partir de un ejercicio de interpretación de la información recolectada a la luz de la perspectiva crítica neogramsciana en relaciones internacionales (Cox, 1981; 1986; Gill, 2008; 2012; Worth, 2013) y las teorías de los movimientos sociales (Andretta, Della Porta, Reiter, y Mosca, 2006; Benford y Snow, 2000; Melucci, 1994; Reitan, 2007; Tilly, 2010; Tarrow, 2007). Complementariamente, un acercamiento a los casos de estudio tiene como punto de 
partida sus elementos estratégico-políticos, en este caso demandas o plataformas políticas y elementos identitarios, que dan cuenta de un encuentro entre estos y el proceso global que lleva a cabo LVC.

Para tales fines, se analizó la plataforma política del CNA y la manera en que sus propuestas dan cuenta de alianzas globales y marcos de acción más amplios dentro de la lucha campesina. Además de hacer una revisión documental en las páginas web de los movimientos, se realizó un trabajo de campo entre los meses de marzo y abril de 2018 en la sede del Instituto Agroecológico Latinoamericano, IALA, María Cano, ubicada en el municipio de Viotá, Cundinamarca, con el fin de participar en actividades técnico-políticas y clases, y realizar un grupo focal con jóvenes (de entre 18 y 27 años) miembros de organizaciones campesinas de todo el país asociadas a Fensuagro. También, en el mismo periodo, se llevaron a cabo cinco entrevistas semiestructuradas a líderes y miembros de ambos movimientos.

El trabajo se divide en tres secciones que permiten conocer y analizar los dos casos dentro de LVC, así como identificar los puntos de encuentro entre los mismos. La primera sección presenta una contextualización acerca de LVC y los principales movimientos campesinos colombianos involucrados en ella, con el fin de problematizar la relación del campesinado local con un marco global de acción e identificación. La segunda sección profundiza la relación de enmarcamiento global y de potenciamiento de las iniciativas locales mediante un análisis de los aspectos globales puestos en diálogo con los elementos y los procesos propios de cada una de las organizaciones nacionales. Finalmente, la tercera sección ofrece algunas reflexiones que buscan trazar puntos comunes de los procesos colombianos analizados y precisar algunas herramientas teóricas útiles para el estudio de esos enmarcamientos globales arraigados en lo local.

\section{Orígenes organizativos en lo global y lo nacional}

LVC nació en 1992 tras el Congreso de la Unión Nacional de Agricultores y Ganaderos, UNAG, en Managua, Nicaragua. Líderes y lideresas campesinas de Europa, América Central y América del Norte manifestaron su inconformismo frente a las privaciones generadas por los programas de "desarrollo" y por las hasta entonces recientes - pero ya deficientes- medidas neoliberales, una propuesta que además buscaría 
producir y difundir modelos alternativos en el mundo rural (Menser, 2008). Desde entonces, su alcance a nivel mundial se ha hecho bastante robusto y sus apuestas han llegado a muchos rincones campesinos del mundo mediante la participación de asociaciones y organizaciones locales, que a su vez nutren el acervo global de $\mathrm{LVC}^{1}$.

Sus demandas centrales se pueden resumir en soberanía alimentaria, tierra, agua y territorio, solidaridad internacional, agroecología y semillas, justicia climática y medioambiental, y derechos del campesinado (LVC, 2018), configurando una agenda contrahegemónica (Worth, 2013) frente a fuerzas sociales como las corporaciones transnacionales (Cox, 1981), a prácticas e ideas como los agronegocios, el capitalismo, el libre comercio y el patriarcado (Cox, 1981; Sklair, 2003). Desde sus inicios, varias campañas e iniciativas centradas en países como Corea del Sur, Tailandia, México, Estados Unidos y Brasil, entre otros, dotaron de diversidad creativa las estrategias y los modos de hacer efectivas sus demandas, frente a lo que cabe preguntarse si las organizaciones colombianas - que han trabajado dentro del marco de un fuerte contexto de conflicto rural-, han participado con la misma intensidad y han logrado promover su propia internacionalización desde LVC (Tarrow, 2007).

La problemática de la propiedad de la tierra ha sido ampliamente estudiada y existen algunos consensos acerca de la ausencia y fracasos de verdaderas reformas agrarias (Berry, 2002), la asignación política de los derechos de propiedad sobre la tierra (Legrand, 1986), la desigualdad socioeconómica y los conflictos violentos asociados a estas dinámicas, y cómo estos elementos han hecho del campo colombiano un escenario de constante disputa política. Esta situación, además, se precarizó desde la década de 1990 debido a la profundización de políticas neoliberales en el marco de la apertura comercial, con consecuencias nefastas para los territorios y las comunidades campesinas derivadas de proyectos con clara vocación latifundista, como los cultivos de palma y los agronegocios, por no mencionar la explotación de recursos naturales como la madera y los compromi-

1 Según cifras oficiales del movimiento, cuentan con más de 182 organizaciones en 81 países de todos los continentes, sumando más de 200 millones de campesinos y campesinas asociadas (LVC, 2018). 
sos derivados de la proliferación de tratados de libre comercio en la segunda década del siglo XXI.

Desde 1992, un año después de la puesta en marcha formal de la apertura económica promovida por el gobierno del entonces presidente César Gaviria (Partido Liberal, 1990-1994), ya existían reivindicaciones y denuncias de las consecuencias de este nuevo modelo sobre la vida de los trabajadores en el campo. Entre ellas se cuentan denuncias por la pérdida de identidad cultural y de biodiversidad, la pérdida de seguridad alimentaria, el impacto económico en la producción nacional debido al aumento de las importaciones, el deterioro en las condiciones de vida, el empobrecimiento tecnológico dada la presión de la especialización productiva acompañada de poco apoyo estatal, entre otras (Corrales y Forero, 1992). El cambio de modelo que prometió la llegada del progreso mostró que no solo iba a ser un mejoramiento engañoso, sino que incluso excluiría al campesinado como sujeto digno y de derechos.

En este nuevo contexto, la producción a gran escala, la búsqueda de eficiencia, el aumento de las importaciones debido al libre comercio, sumados a procesos de violencia y urbanización crecientes y conectados (ACVC, 2001), contribuyeron a la llamada descampesinización del campo colombiano. Se consolidó la mentalidad empresarial en el campo, sin los campesinos, con lo que la producción de alimentos se concentró en los grandes empresarios y los latifundistas; la participación del campesinado se restringió, haciéndolo disfuncional al modelo y reduciéndolo a mano de obra barata, cuando aún era necesaria. En otras palabras, se pasó de un modelo en el que el campesinado es explotado pero incluido, a uno en el que es explotado y excluido (Tobasura, 2009). Desde entonces se ha instalado una visión de desarrollo que implica un sector rural afectado por regímenes macroeconómicos internacionales que afectan las condiciones de vida del campesinado y su territorio. Unas presiones políticas y económicas que reducen al campesino a un "siervo sin tierra" (Molano, 2015) y a lo rural a una simple producción de alimentos que ignora la "multifuncionalidad que se desarrolla en los territorios y de la que hacen parte diversos actores" (Melo, 2016, p. 3) con el fin de vivir dignamente.

Ante toda esta serie de procesos adversos y presiones estructurales a la vida en el campo, es que las organizaciones sociales campesinas 
-sindicatos, asociaciones, coordinadoras agrarias, zonas de reserva campesina o comunidades de paz- han canalizado las demandas y reivindicaciones campesinas en Colombia. Organizaciones como Fensuagro y el CNA trabajan activamente por el fortalecimiento del campesinado como sujeto político organizado que defiende su derecho a vivir dignamente trabajando su territorio y, para este propósito, mantienen enlaces estratégicos con LVC.

Fensuagro nació en 1976 bajo el nombre de Fensa, en respuesta a la incumplida reforma agraria pos-Frente Nacional y pasó a llamarse Fensuagro en 1987 con el nacimiento de la Central Unitaria de Trabajadores. Es una organización que busca congregar al campesinado en solidaridad con los demás sectores populares en la lucha por la tierra, una verdadera reforma agraria, derechos laborales y, más recientemente, defensa medioambiental e incluso la misma soberanía alimentaria promulgada en su mayoría por LVC (Fensuagro, 2009). En su vinculación con el movimiento campesino global inauguró el IALA, en Viotá, Cundinamarca (Fensuagro, 2017), que se suma a otros ocho que existen en la región y buscan generar estrategias educativas, de difusión y creación de conocimiento local agroecológico como modelo de producción más consciente.

El CNA, por su parte, es un movimiento campesino fundado y ratificado tras los Foros Nacionales Agrarios de 1997 y 1998 que se dieron en respuesta a las consecuencias negativas de las reformas neoliberales de los años 90. Inició con la pretensión de articular organizaciones para preservar las comunidades rurales y construir a partir de ellas una nueva sociedad basada en justicia social (CNA, 2009). En ello, ha construido una política exhaustiva y transformadora que aspira a la creación de nuevas condiciones alternativas para el campo colombiano (CNA, 2009). En ambos casos, el apoyo de LVC resulta fundamental para la dinamización de las propuestas más recientes, la realización de eventos y la difusión de información relacionada con el mismo punto.

\section{Construyendo movimiento global en y desde Colombia}

El CNA y Fensuagro son los dos casos paralelos de acción colectiva en el contexto colombiano que se ponen en diálogo con el marco pro- 
puesto por La Vía Campesina. Las experiencias de estos movimientos dan cuenta de la manera en la que las campesinas y campesinos colombianos organizados, han sabido enmarcarse globalmente para potenciar sus luchas, visibilizarse y buscar una unión en sus discursos y demandas.

A partir del trabajo de observación, de las entrevistas, los grupos focales y análisis de documentos oficiales y prensa fue posible establecer que las plataformas políticas, las manifestaciones, los eventos conjuntos y los proyectos pedagógicos se constituyen como estrategias dentro de los repertorios de los movimientos y de LVC, que se profundizan para trazar no solo los sentidos de esta articulación, sino sus efectos y proyecciones. Con el fin de comprender estos procesos, es preciso empezar por conocer las líneas de movilización que caracterizan a LVC como movimiento campesino capaz de enmarcar las luchas campesinas a nivel global. LVC se define a sí misma como:

un movimiento internacional que reúne a millones de campesinos, agricultores pequeños y medianos, sin tierra, jóvenes y mujeres rurales, indígenas, migrantes y trabajadores agrícolas de todo el mundo. Constituido sobre un fuerte sentido de unidad, la solidaridad entre estos grupos, que defiende la agricultura campesina por la soberanía alimentaria como una forma de promover la justicia social y la dignidad, y se opone fuertemente a agronegocios que destruyen las relaciones sociales y la naturaleza. (LVC, 2017).

Así, es posible observar que desde el primer momento se ponen de manifiesto elementos centrales en cuanto a la representatividad de la organización, sus principios y valores, las luchas que defienden e incluso los antagonismos que motivan el cambio. Annette Desmarais (2007), investigadora y campesina experta en el proceso de desarrollo de LVC, resume el posicionamiento de la organización así: en términos estructurales, emerge en un contexto de economía globalizada a través de los mecanismos de la Organización Mundial del Comercio OMC-, hecho que determina en buena medida su naturaleza anticorporativista; su identidad, en consonancia, se construye a partir de su autorreconocimiento como "gente de la tierra" (p. 75) y en antagonismo con las corporaciones transnacionales; $y$, sus metas centradas en la necesidad de cambio social interpretado a partir de las interacciones de la misma sociedad civil de la que hacen parte. 
A lo largo de su existencia, LVC ha logrado reunir al campesinado bajo unos mínimos comunes producto de negociaciones y espacios de encuentro. Un espíritu democrático que se complementa con una identidad flexible de gente de la tierra que se liga a sus actividades vitales sin perder particularidades territoriales. Es por eso que la articulación buscada gira en torno a unos antagonismos comunes y a unos fortalecimientos globales.

Sus antagonismos son trazados a través de una lectura sociopolítica y económica global que rechaza explícitamente las políticas neoliberales y las instituciones internacionales que sostienen sus principios como lo son la OMC y las organizaciones de Bretton Woods. Tras un reconocimiento de los agravios comunes a nivel mundial y los cambios económicos o decisiones políticas que los sostienen, la manera en que se enmarcan los problemas se globaliza y permite tejer puentes mucho más claros para todas las resistencias campesinas. En palabras de Benford y Snow (2000): un enmarcamiento de diagnóstico.

Por otro lado, un enfoque positivo de lo que une al campesinado global apunta a construir identidades comunes frente a la relación con la tierra y su aprovechamiento armónico con la finalidad de alimentar la humanidad. En líneas generales, identitariamente tratan de ser flexibles para permitir adaptabilidad sin perder de vista objetivos comunes; lo que Desmarais (2007) reconoce como el "fino balance entre realidades locales y acciones globales" (p. 135). Es así como el elemento identitario se complementa con una lectura específica de la estructura de oportunidad política internacional (Tarrow, 2007) para promover líneas de acción, principios organizativos e innovaciones en los repertorios. Todo esto, es puesto en práctica, promovido y complejizado nacional y localmente en Colombia por el CNA y Fensuagro.

\section{El CNA: líneas programáticas y de organización ${ }^{2}$}

En primer lugar, desde su creación su objetivo es construir una organización nacional, agraria y rural, donde puedan converger distintas expresiones organizadas del mundo rural. A través de la organización se busca promover la preservación de las comunidades rurales y cam-

2 Sección basada en: Plataforma Política del CNA (2009), y entrevista con Germán Bedoya en 2018, líder campesino del CNA. 
pesinas, alcanzar condiciones dignas de vida para la población rural y construir una nueva sociedad a partir de criterios de equidad, paz, justicia social y soberanía popular (CNA, 2009). Cuenta con más de 25 asociaciones campesinas en todo el país ${ }^{3}$, desde el 2008 hace parte del movimiento social y político Congreso de Los Pueblos - espacio desde el cual tiende puentes con otros sectores populares-y hace parte de redes organizativas a nivel latinoamericano y mundial como LVC o su asociada regional, la Coordinadora Latinoamericana de Organizaciones Campesinas, CLOC.

Su vinculación con estas redes y movimientos globales se fundamenta en la lectura crítica que hace del contexto político, cultural y económico, tanto nacional como global. En el ámbito económico-productivo la posición se basa en reconocer las transformaciones de las dinámicas económicas desde una matriz de pensamiento desarrollista y con reductos coloniales que sustenta el funcionamiento del mercado internacional (CNA, 2009). Esto implica hablar de manera explícita de los cambios traídos por el neoliberalismo, sin dejar de lado la herencia colonial de un modelo que termina por afectar al campesinado. Se ponen de manifiesto las violaciones de derechos humanos a la población campesina y su organización, el mal manejo de la tierra - despojo y concentración - e incluso la violencia y el narcotráfico como elementos de la realidad colombiana que son producto de unos ordenamientos estructurales del modelo capitalista/colonial que quiere al campesino y a la campesina fuera del campo. La integración al mercado internacional hace que los monocultivos y los grandes agronegocios sean la constante que afecta las formas de producción campesina, cultivo, uso y tenencia de la tierra, protección de semillas y conocimientos propios, y acceso al agua como derecho.

Para el CNA, los conflictos culturales que afectan al campesino y la campesina en su integralidad giran en torno a la predominancia de la idea de que el sujeto del campo debe ser el "empresario rural" (CNA, 2009, p. 35). Es decir, se parte de un no-reconocimiento de la vida y sociedad campesina a pesar de sus aportes sociales, culturales y ambientales. Los modelos económicos - que ponen sobre el campo prio-

3 La lista completa de las organizaciones asociadas al CNA puede ser consultada en: https://cnagrario.org/organizaciones-cna/ 
ridades e imperativos de organización-, quitan capacidad política al campesinado, atentan contra la diversidad cultural e incluso venden una idea de no-futuro en las nuevas generaciones de campesinos y campesinas. Toda una afectación que desde lo simbólico se nutre para desvalorar lo campesino y ser funcional a una idea de campo neoliberal al servicio del mercado internacional y los grandes agronegocios.

Los conflictos en materia política hablan de la poca incidencia con la que se encuentra el campesinado para decidir su futuro. La manera en la que se organiza y actúa el Estado - en función de intereses económicos neoliberales- hace que la formulación de políticas públicas sea centralizada y con una participación de la sociedad civil sin impacto real, lo cual hace que las organizaciones tiendan a desaparecer o busquen otros medios de acción y visibilización. Además, el CNA reconoce la violencia como uno de los grandes factores para el acallamiento del campesinado y el reordenamiento del territorio. Se podría decir que leen la violencia como medio funcional al establecimiento del sistema. Esto permite ver que el tipo de conflictos reconocidos como territoriales son transversales a la historia de la lucha campesina en Colombia, y entender que el territorio está y quiere ser ordenado para los intereses económicos. Se habla del campo y el territorio como un espacio vaciable. Un manejo del territorio nutrido por despojo, control militar y gestión extractivista, mucho de lo cual proviene de lógicas coloniales de una modernidad que sigue intentando asentarse por la fuerza y de manera desigual en Colombia.

Ahora bien, más allá de las visiones y posturas del CNA propias de la naturaleza del escenario rural colombiano, es importante resaltar la lectura que se hace de las causas. Al verlas como propias de un sistema económico internacional, son leídas en clave global y más allá de las mismas particularidades de Colombia. Es fundamental aquí comprender los cambios traídos por el neoliberalismo, pero sin dejar de verlos como la nueva cara de unos mismos procesos estructurales. Esto significa poner en primer plano los antagonismos no solo en el Estado y las lógicas empresariales transnacionales, sino también en la institucionalidad internacional que los promueve: unas primeras líneas de acercamiento a los postulados de LVC y su marco de acción colectiva global. A partir de esto, el CNA hace una propuesta política y organizativa que permite ser integral a la hora de ofrecer soluciones 
a los conflictos identificados. Basada en humanismo, integralidad, democracia real como ideal de sociedad, sostenibilidad, equidad y diversidad, establece un marco a partir del cual entender y enfocar la lucha campesina y popular.

En esta propuesta el territorio tiene gran protagonismo, dado que de él se desprenden elementos integradores, en la medida en que se entiende como fuente de identidad, cultura, de vida y como patrimonio material. La soberanía también juega un rol clave, pues es la que permite actuar en pro de las capacidades para definir su propio futuro en autonomía; una soberanía agroalimentaria que ponga a la producción y al consumo en función de los intereses y necesidades del campesinado. Sumado a esto, las acciones deben propugnar por la unidad como modo de articulación de la diversidad (CNA, 2009), postura de acción que hacia 2009 ya contaba con puntos de encuentro organizativos con las propuestas globales de LVC.

En conversación con Germán Bedoya ${ }^{4}$, líder campesino del Líbano, Tolima, y activista central del proceso de articulación del CNA con LVC, salen a relucir de manera más explícita las líneas de acción donde se puede hablar precisamente de un crecimiento y un trabajo conjunto entre CNA y LVC. Bedoya plantea seis temas en los cuales el aporte de LVC ha sido fundamental, ya sea para ampliar el alcance de las luchas, como para poner ampliar la agenda o para visibilizar avances. El primero de ellos es la lucha por la territorialidad, es decir, el sentido que se le quiere dar a la tenencia de la tierra. Si bien se reconoce la fuerte lucha que se ha dado a lo largo de los años por la tenencia de la tierra ante la concentración y el despojo, los aportes de las reflexiones de LVC han permitido que en el seno del CNA se piense con mayor compromiso en el "para qué" de la tierra y no solo tenerla por tenerla. Esto en la práctica implica ir en búsqueda de verdaderos proyectos en cuanto a la manera de administrar, gobernar y organizar el territorio según sus propias visiones del campo y sus propios principios y fines. De hecho, dentro de la misma Plataforma Política del CNA se habla de la territorialidad como "una especie de identidad espacial, un sentimiento de pertenencia a una parte de nuestro país, a un pedazo (...) permite también construir un sentido de exclusividad sobre esa porción de

4 Conversación realizada el 23 de marzo de 2018 en la ciudad de Bogotá. 
tierra" (CNA, 2009, p. 6). La territorialidad campesina pasa a ser parte transversal del proyecto y ofrece elementos reivindicativos, siendo vista como estrategia organizativa y como fuente de identidad.

Un segundo elemento es el tema de las semillas. Según Bedoya, LVC ha permitido ampliar la visión crítica y la importancia del tema, mostrando cómo la defensa por las semillas nativas es un elemento clave en la lucha por la soberanía alimentaria. En la Plataforma se reconoce múltiples veces la centralidad del tema y la responsabilidad de empresas e instituciones internacionales frente a la problemática, ya sea por los químicos y las modificaciones genéticas, o bien, por los impedimentos legales y biológicos para mantener y producir la semilla propia.

Un tercer elemento es la protección del agua. Al respecto, LVC ha sido clave para aumentar la conciencia en relación con la vitalidad del agua $^{5}$ como elemento base para la subsistencia y para potenciar su defensa ante las amenazas de privatización, contaminación y pérdida. Una vez más, la Plataforma Política del CNA parece enmarcarse desde el 2009 en esa lucha al reconocer la centralidad del agua como parte de los conflictos territoriales y económicos que afectan no solo al campesinado, sino a toda la sociedad (CNA, 2009).

En cuarto lugar, se encuentra la lucha por la reivindicación de las mujeres y su rol en el campo. A pesar de ser una lucha más amplia, se ha sabido nutrir la movilización campesina de los aportes del feminismo para dar el lugar merecido a las mujeres en el campo y en la organización. Lucha que ha hecho muy explícita LVC y ha buscado llevar a los rincones de todas sus organizaciones asociadas. El mismo Bedoya resalta la creación de la Secretaría de la Mujer del CNA como una victoria en el contexto de la organización y del país, reconociendo el rol que tuvo LVC para lograrlo.

Un quinto elemento de articulación es el reconocimiento del campesino y la campesina como sujetos políticos, una reivindicación constante en las luchas campesinas colombianas. Así, la centralidad de esta reivindicación en LVC ha permitido visibilizar mucho más los objeti-

5 Para un breve acercamiento a los amplios planteamientos de LVC frente a la protección del agua revísese: https://viacampesina.org/en/in-defense-of-food-sovereigntystop-water-grabbing/ 
vos que por décadas han tenido organizaciones como el CNA. Tal es el caso de las acciones llevadas a cabo por LVC alrededor de la Declaración de los Derechos de los Campesinos en el seno de la ONU, que desde un foro internacional llegaron a tener impactos en lo local y lo nacional en un proceso de "efecto boomerang" (Keck y Sikkink, 2000).

Como sexto elemento se encuentra el reconocimiento de elementos simbólicos comunes y conmemoraciones globales que hacen visible la lucha campesina y la unen a nivel global o nacional. Ejemplos de ello son la conmemoración de días como el 17 de abril ${ }^{6}$-Día Internacional de la Lucha Campesina - o la celebración de congresos internacionales cada cuatro años, en los cuales participa activamente el CNA en representación de Colombia. La identidad creada alrededor de LVC, sus colores, sus símbolos, sus arengas y sus mártires ${ }^{7}$, permite la unión del campesinado más allá de lo programático y brinda elementos simbólicos y discursivos para nutrir la lucha de sentimiento y solidaridad, incluso en terrenos como el de la imaginación (Appadurai, 2001). En palabras de Melucci (1994), esto equivale a complementar las interacciones negociadas y los objetivos comunes, con reconocimiento emocional y solidaridad.

\section{Fensuagro: la formación como punto de encuentro}

Fensuagro, cuya organización data de 1976, tiene como objetivo central la construcción de un movimiento agrario y campesino que recobre la identidad de clase y que incorpore la lucha y la movilización social como vías para alcanzar una reforma agraria democrática e integral. Retoman la consigna de la Revolución mexicana de "la tierra para quien la trabaja", en su lucha por la redistribución de la tierra (Fensuagro, 2009). Por eso, su reivindicación central está en las carencias materiales y de infraestructura del campesinado, por lo que busca una

$6 \quad$ El 17 de abril se rememora anualmente la masacre de Eldorado dos Carajás, donde 19 campesinos Sin Tierra fueron asesinados en 1996 en Pará, Brasil. Además, se celebran días como el 8 de marzo (Día Internacional de la Mujer), el 10 de septiembre (Día Internacional en la Lucha Contra la OMC y los TLC), el 16 de octubre (Día de la Acción por la Soberanía Alimentaria y en Contra de las Corporaciones Transnacionales), el 25 de noviembre (Día de la Eliminación de la Violencia contra la Mujer) y el 3 de diciembre (Día Mundial de la Acción contra los Agrotóxicos).

7 Se destaca la muerte y recuerdo simbólico del campesino coreano Lee Kyung Hae, quien se inmoló apuñaleándose a sí mismo durante una manifestación global en Cancún, México, en 2003 (Braga, 2012). 
transformación social basada en la justicia social al lado de los trabajadores del campo y la ciudad (Fensuagro, 2009).

Se diferencia del CNA en la trayectoria de alianzas internacionales debido a que, según algunos de sus dirigentes, Fensuagro se incluye en las organizaciones que participaron en la creación misma de $\mathrm{LVC}^{8}$. De acuerdo con testimonios recogidos para esta investigación, la creación de LVC trasciende las fundacionales conferencias de Managua (1992) y Mons (1993); se argumenta que hubo un proceso anterior que fue esencial para alcanzar dicha meta organizativa. Este proceso tuvo lugar en América Latina, incluida Colombia, tras las conmemoraciones de los 500 años de la llegada de los españoles a las Américas, que traían el bagaje de organizaciones y movimientos populares de la región. En ese proceso, los encuentros campesinos fueron comunes y los intercambios de experiencias fueron centrales. Fensuagro estuvo presente en ellos y, por lo tanto, acompañaría los procesos fundacionales, según la narrativa oficial de LVC, de 1992 y 1993. Debido a esto, Fensuagro pasa a ser parte en primer lugar de la CLOC y luego de la que sería LVC. Este aspecto es crucial para entender el sentido que tiene LVC para Fensuagro y, por lo tanto, la manera en la que se han desarrollado sus apuestas conjuntas.

Como producto de una relación bastante estrecha desde el mismo 1993, Fensuagro y LVC llevan a un punto crucial el trabajo organizativo en el año 2017 con la inauguración del IALA María Cano. El último de una red de institutos educativos campesinos en América Latina que, alrededor de la agroecología como apuesta de formación técnica, paralela con la formación política, buscan fortalecer las organizaciones

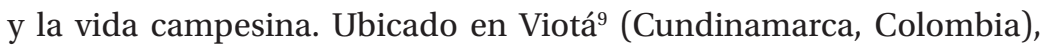
cuenta con 16 hectáreas, más de 20 alumnos jóvenes campesinos por cohorte y un equipo permanente con conocimiento pedagógico, técnico y político. En el IALA se busca consolidar al conocimiento como herramienta de resistencia en la lucha epistemológica, además de pro-

8 Información obtenida de conversación informal con Nury Martínez de Fensuagro y LVC.

9 No es un detalle menor la realización de este proyecto en un municipio como Viotá, puesto que su historia está estrechamente ligada a las luchas agrarias, la desconcentración de la tierra, las dinámicas cafeteras, la presencia y retaguardia del Partido Comunista Colombiano, e incluso disputas con paramilitares. Para profundizar: Cepeda-Ladino, 2013; Gilhodes, 1988; Agencia Prensa Rural, 2008; 2009; Tovar, 1975. 
pugnar por la soberanía alimentaria a través de prácticas agroecológicas (Kaur, 2017), que tienen sus raíces en las propuestas del movimiento global campesino.

La agroecología es promovida desde la misma LVC como método para materializar los ideales alrededor de la soberanía alimentaria y ha sido adoptada por numerosos movimientos rurales alrededor del mundo. Estos la usan no solo como metodología productiva, sino como "elemento clave en la construcción de la soberanía alimentaria y como herramienta de lucha, defensa, (re)configuración política y transformación de tierras y territorios disputados en territorios campesinos, en un proceso de recampesinización" (Rosset y Martínez, 2016, p. 277). Se habla entonces de una herramienta práctica, transdisciplinar, participativa, horizontal y orientada al cambio (Kaur, 2017) que combina integralmente elementos científicos con elementos prácticos y políticos de movilización social en pro de un cambio social que, además, rescate saberes comunitarios y ancestrales. Es una metodología que conecta lo político, lo cultural, lo económico, lo social y lo ecológico, siempre con un componente de reto al sistema capitalista y neoliberal derivado de cosmovisiones distintas a la moderna occidental.

El propósito del IALA es que a través de la agroecología como propuesta integral se fortalezca al campesinado y su lucha organizativa. Es además un espacio para intercambio de saberes por medio de su metodología "campesino a campesino" ${ }^{10}$ y por su sentido transnacional, que permite encuentros con estudiantes, líderes y profesores de otras partes del mundo, especialmente de América Latina. Una escuela contextualizada tanto en lo local como en lo global que contribuye, entre otras, al diálogo y a la articulación interétnica (Kaur, 2017). Incluso plantea ser una iniciativa que piensa complementar y profundizar la agroecología que está limitadamente consignada en los Acuerdos de Paz de manera despolitizada y solo en el papel (Kaur, 2017).

Ahora bien, el trabajo con estudiantes del IALA, miembros de la Coordinación Político Pedagógica del Instituto y lideresas a cargo del

10 Metodología propuesta desde el intercambio de conocimiento, prácticas y cosmovisiones entre pares basada en el diálogo horizontal. Tiene orígenes en las posturas de Paulo Freire. Para ampliar en dicha metodología: Kaur, 2017; Martínez-Torres y Rosset, 2014. 
proceso de LVC en Colombia desde Fensuagro, permiten trazar algunos elementos clave para entender la articulación de dichas organizaciones la manera en la que se lee el contexto nacional e internacional; la forma en que se aporta estratégicamente a la organización de la lucha; y la manera en la que se establecen identidades campesinas.

Siguiendo los planteamientos de Melucci (1994), quien señala que la identidad colectiva se genera también a partir de cómo se percibe la realidad social (como se evalúan las capacidades y expectativas), es crucial acercarse al modo en que los participantes leen la estructura política nacional e internacional y los vínculos de esta con su forma de identificarse en la lucha. Desde la visión de los educandos la situación del campesinado es "crítica" en términos ambientales, de infraestructura, económicos, territoriales y es leída como una realidad de larga data. Elementos ya comunes como la lucha por las semillas, contra los agrotóxicos y sus orígenes en las multinacionales aparecen para nutrir los agravios que llenan desde el inicio el discurso del joven campesino. Reconocen a su vez una hegemonía capitalista-neoliberal que genera condiciones para la descampesinización del campo, una situación desfavorable para un campesinado que entra entonces también en una lucha cultural por sus costumbres y su visión de mundo.

Profundizando en el tema con lideresas como Nury Martínez ${ }^{11}$ y Luz Dary Molina ${ }^{12}$, el discurso parte de dos lecturas del escenario internacional. En primer lugar, uno político basado en un sistema hegemónico donde espacios como la OMC o el Banco Mundial definen los lineamientos de la política global que privilegia los grandes capitales, monocultivos y extractivismo y que no quiere campesinos o campesinas en el campo. En segundo lugar, se habla de un ámbito internacional de acción colectiva campesina, es decir, uno que logra que las luchas sean globales. Aquí resalta el papel de LVC como parte de un escenario internacional que favorece al campesinado para visibilizar las problemáticas, proteger y defender los territorios de una mejor forma y en general "relacionar todo de una manera más global". Esto permite el reconocimiento del campesinado global como sujeto de derechos y

11 Conversación con Nury Martínez realizada en Viotá el 21 de marzo de 2018 y entrevista realizada en Bogotá el 9 de abril de 2018.

12 Conversación y entrevista realizadas con Luz Dary Molina en Viotá el 12 de abril de 2018. 
el entendimiento de que la lectura que se hace del escenario internacional por parte de movimientos campesinos colombianos pasa por la comprensión de sistemas globales a modo de antagonismos, y de iniciativas globales de movilización, a modo de oportunidad política, para actuar y dar más fuerza a las luchas.

Esto se complementa con la manera en la que tanto líderes como participantes de la organización ven su relación con el Estado. Los líderes hacen otra distinción clara: el gobierno y el Estado. Reconocen que a los gobiernos no les interesa mirar al campo; gobiernos que incumplen y que toman decisiones que son funcionales a los modelos neoliberales criticados, lo que lleva a pensar que desde la institucionalidad misma se reproduce ese no-reconocimiento de los campesinos y campesinas. Así pues, a pesar de que se reconozca la diferenciación Estado-gobierno, el sentido de la relación Estado-sociedad (Gramsci, 1973) percibida acá es la de un Estado como institucionalidad que debería atender las necesidades del campesinado y permitir sus libertades y derechos, pero que ha sido cooptado por los intereses y voluntades contrarias de gobiernos funcionales a modelos injustos.

En materia organizativa y de repertorios de acción, para casi todos los entrevistados lo hecho por el IALA, Fensuagro y LVC son iniciativas que responden - $\mathrm{o}$ intentan responder- a las problemáticas ya reconocidas del campesinado a nivel global y local, a su vez que son fuente de identidad y de unidad de lucha. Los jóvenes educandos reconocen al IALA como una "trinchera del pensamiento" y de formación revolucionaria para el ámbito personal, pero siempre enfocada en "contribuir a los cambios sociales, culturales y estructurales". Es la continuación de una lucha de generaciones y un "sueño cumplido" para dar nueva esperanza a través de la formación integral de campesinos y campesinas líderes. Siendo a su vez un paso para fortalecer procesos organizativos, empoderar jóvenes y aportar a la transformación del país. Las percepciones acerca del IALA se complementan con aquellas del LVC. A este movimiento global lo ven también como una "trinchera" de las luchas del campesinado a nivel mundial, como un ejemplo de unidad, como un camino en que se encuentran muchas formas de lucha, como una estructura de dirección de las luchas sociales y un hogar de los que luchan, entre otras. De igual forma, por diferentes que sean las palabras usadas para catalogarla, LVC es reconocida por todos gracias a su 
defensa de las demandas y los elementos culturales del campesinado en sentido de unión y de transformación.

Estas visiones cobran mayor peso una vez se recoge lo dicho por líderes de Fensuagro y del mismo IALA. Para Nury Martínez sencillamente "LVC es un sueño" y un camino que llena de esperanza. Es una manera de mirar el mundo y entender que los problemas que se tiene los tiene todo el mundo. Ella considera que LVC en las organizaciones ha enseñado a entenderse, a quererse, a compartir y a entender la igualdad; incluso de género. Alexander Rodríguez habla de LVC como referente internacional de la lucha del campesinado que ha permitido tener objetivos más claros, pero que también LVC se nutre de los aportes de organizaciones como Fensuagro, cuya experiencia de movilización, lucha y formación ha sido vital para los procesos de organización campesina a nivel latinoamericano. Mientras tanto, para Luz Dary Molina, el aporte de LVC a lo local es la convicción en la solidaridad y en ver al campesino y la campesina con sus particularidades, pero bajo una misma apuesta. Toda una serie de elementos que son aportados en espacios de formación y visibilización a través de campañas conjuntas y denuncia globalizada. Incluso se llega a reconocer la importancia de LVC para generar unidad y superar diferencias a nivel nacional, como lo es la relación entre los mismos Fensuagro y CNA.

Además de esto, varios testimonios dan cuenta de la importancia del IALA como una propuesta de paz enmarcada en la implementación de los acuerdos firmados en 2016 entre el Gobierno de Colombia y la extinta guerrilla de las FARC-EP. Nury Martínez dice que el IALA es una forma en la que Fensuagro aporta a la construcción de la paz, pues su propuesta formativa busca el diálogo, la democratización y la muestra de oportunidades a los jóvenes más allá de la guerra. Además, se busca que esta apuesta político-pedagógica contribuya a implementar la Reforma Rural Integral. Incluso, LVC hace parte de la mesa de seguimiento al punto 1 conformada además por la FAO, el PNUD y la Unión Europea $^{13}$. Sin embargo, no debe olvidarse que aquellos que representan a LVC en estos espacios de contexto colombiano son los mismos lí-

13 Información obtenida en conversación informal con Nury Martínez de Fensuagro y LVC. De igual manera puede ser ratificada en: http://nacionesunidas.org.co/ blog/2017/07/21/union-europea-fao-pnud-y-via-campesina-reiteran-apoyo-a-la-implementacion-del-punto-1-del-acuerdo-de-paz/ 
deres de otras organizaciones participantes, como pueden ser el CNA, Fensuagro o cualquiera de las seis organizaciones colombianas dentro de $\operatorname{LVC}^{14}$.

Estas visiones permiten comprender la importancia que ha logrado tener LVC en las formas de entender la lucha campesina en Colombia desde los mismos sujetos que hacen parte de ella. Incluso desde una posición organizativa se permite aclarar que la relación entre movimientos no es del todo jerárquica en sus aportes y funcionamiento, pues se entiende que las mismas organizaciones locales son la representación de LVC en Colombia. En este caso concreto, para el año 2018 Fensuagro, por rotación, era la organización que estaba al frente de LVC para América Latina. Esto implica que LVC en Colombia era Fensuagro y que las articulaciones en lo local son tan estrechas que todo acto político, de movilización, formación u organización, hace parte de un mismo marco de LVC localizado en la realidad colombiana.

Ahora bien, el último tema fundamental es el identitario, un elemento transversal a las motivaciones de lucha y a todos los procesos cognitivos y culturales que llevan a la acción, además de ser uno de los aspectos que más alimenta la fuerza de LVC. En las concepciones de los educandos del IALA, el ser campesina o campesino está ligado con objetivos colectivos como: producción de alimentos, transformación de la sociedad, conservación de tradiciones, relación estrecha con el territorio más allá de la explotación económica, la protección de la naturaleza, entre otros. Igualmente, para líderes como Alexander, Luz Dary o Nury, el ser campesino o campesina pasa en primer lugar por su íntima relación con la tierra. Se reconocen a sí mismos como seres sociales y culturales que los caracteriza su fuerte relación con el territorio y con la naturaleza - que no es vista como mercancía-, incluso al punto de ver al territorio como parte de sí, como el mismo hogar. Esto además con un fuerte componente de comunidad que lleva a entender las problemáticas y las soluciones como compartidas. Igualmente, de los testimonios recogidos, es posible trazar una autocomprensión del campesinado como un sujeto cultural, social y político que se define

14 Además de Fensuagro y el CNA, pertenecen a LVC: la Asociación Nacional de Zonas de Reserva Campesina (ANZORC), el Movimiento Ríos Vivos, el Proceso de Comunidades Negras (PCN) y la Federación Nacional de Cooperativas Agropecuarias (FENACOA). 
desde su relación mutua con el territorio, ya sea desde su producción alimentaria, o bien, desde su defensa política y organizativa. Es lo que Luz Dary Molina define como un "sujeto activo, dinámico, permanente en el proceso de la cadena productiva de la vida y del alimento".

\section{Reflexiones finales}

Este repaso por los elementos que unen el accionar de los movimientos campesinos colombianos con aquello que representa y evoca LVC permite ver que no implica una subordinación de los procesos locales a uno global externo. Más que una relación jerárquica entre procesos de lucha contra el neoliberalismo, es el encuentro de experiencias y la revitalización conjunta entre lo local y lo global (Cepeda Másmela, 2019). El que organizaciones como el CNA o Fensuagro tomen acciones enfocadas a enmarcarse globalmente no hace que pierdan fuerza en la lectura local de sus situaciones; al contrario, la complementa y le da una perspectiva de lucha mucho más legítima.

Más allá del casi unánime reconocimiento del aporte de la LVC que permite ver la relación entre organizaciones de manera armónica, existen pequeñas rupturas entre el marco general de LVC y la lectura que hacen los movimientos locales. Puede que algunos miembros campesinos y campesinas reconozcan que debe hacerse mucho más que simples movilizaciones o propender por pequeñas reformas, que piensen que el cambio debe hacerse de manera más radical, o que en términos generales quieran buscar acciones y entendimientos que trasciendan lo propuesto por LVC.

Pese a estas críticas incipientes, este proceso de enmarcamiento global permite, por un lado, que haya flexibilidad en la comprensión dentro de la lucha y la acción, lo que permite fortalecerlas y nutrirlas mucho más desde la diversidad. Y por el otro, que aún en las posiciones más radicales se reconozca y se acoja lo propuesto por LVC como un gran avance y como una oportunidad política en sí misma, que es bastante enriquecedora y no debe desaprovecharse en su camino hacia las transformaciones y reconfiguraciones políticas esperadas.

La clave está en entender el rol que juega LVC localmente y la manera en la que toma forma en lo local (Cepeda Másmela, 2019). En los contextos de movilización locales LVC no es un actor externo, sino que 
es el movimiento mismo. Dicho de otra forma, el movimiento local es el que representa y, a la vez, se muestra como (parte de) LVC. El caso colombiano resultó bastante ilustrativo en ese sentido: personas como Nury Martínez, lideresa desde hace décadas de Fensuagro, es actualmente la coordinadora nacional y regional latinoamericana de LVC, sin dejar de ser lideresa local. LVC es el mismo movimiento, los mismos líderes y miembros de la asociación, solo que adoptando un nombre más, que les permite también enmarcar su lucha globalmente. Esto permite entender que se habla de una relación de apropiación directa del conocimiento situado y de las experiencias de lucha locales en el marco mismo de LVC. Una diversidad que en el momento de ser llevada a eventos internacionales o regionales es gestionada de manera democrática y constructiva para nutrir y fortalecer una lucha de acciones locales y globales.

A partir de estas consideraciones, es posible tener algunas líneas finales de reflexión conceptual y empírica. En primer lugar, para comprender los procesos de acción colectiva campesina en términos globales, es fundamental pasar por un análisis integral de los contextos y las estructuras políticas sobre las cuales actúan y ante las cuales resisten dichos movimientos. La clave está en reconocer que el ambiente político o la estructura de oportunidad política, según el concepto acuñado por Sidney Tarrow (1994), debe ser leído en diferentes niveles, desde lo global a lo local, pasando por lo nacional. Cada uno de ellos, visto en perspectiva crítica e integral, como una interacción entre ideas, instituciones y capacidades materiales (Cox, 1981), brinda las claves para entender las tensiones políticas, las injusticias sobre la población campesina e incluso las lecturas que estos movimientos hacen para tomar acciones.

En segundo lugar, entender la política internacional pasa por comprender que existen órdenes mundiales y estructuras políticas internacionales (Cox, 1981) situadas históricamente, que han puesto las condiciones a nivel global para victimizar al campesinado. El sistema mundo capitalista moderno ha sabido universalizar valores y normas que, desde lo político, lo económico e incluso lo epistemológico, niegan otras formas de existir en el mundo y de actuar ante él ((Escobar, 2012, Moore, 2017; 2018). Es así como el neoliberalismo y su racionalidad política (Brown, 2003) difundida a todos los ámbitos de la vida ha 
desplazado muchas de las formas de vida campesina que se piensan por fuera de ese modelo. Es ante estas estructuras globales, promovidas por instituciones, adoptadas por Estados y difundidas por las acciones cotidianas de los individuos, que el campesinado global se levanta y comienza a tomar conciencia de sí. La lectura de los problemas y los antagonismos desde una perspectiva global comienza a generar respuestas también globales en la forma de organizarse y de actuar colectivamente.

En tercer lugar, es necesario entender la relación que ha tenido el Estado con el campesinado. El Estado - que no ha logrado superar estructuras coloniales de organización rural y que sigue buscando la "modernización" del campo de forma deficiente y nunca con la intención de favorecer o escuchar realmente al campesinado-, termina siendo funcional a los órdenes mundiales descritos y no operando como institucionalidad intermediaria para las demandas campesinas. Dinámicas de inoperancia, incumplimiento, represión y agravio constante son las que han caracterizado la relación del Estado con un campesinado colombiano inconforme y victimizado. A pesar de esto, las organizaciones campesinas han construido una agenda de demandas en torno a temas como la reforma agraria real, el acceso a tierras, el reconocimiento político, la participación política, el respeto a la vida y a los derechos humanos, entre otros. Estas reivindicaciones y banderas de lucha han sido exigidas mediante amplios repertorios de lucha como marchas, paros, tomas de tierras, bloqueos, peticiones y acciones legales, entre otras.

Desde la década de los 90, tanto demandas como repertorios han comenzado a ampliarse. La lucha por temas ambientales, agua, semillas nativas, derechos de la mujer, soberanía alimentaria y territorial, se han sumado a las viejas peticiones para ampliar el horizonte de cambio. El campesinado colombiano ha recobrado una mayor fuerza, que se evidencia en paros nacionales desde 2013 para exigir los cambios que se esperaban. Un gran avance en términos de visibilización, más allá del incumplimiento estatal, donde se logró articular problemáticas estructurales nacionales con asuntos globales como el libre comercio.

En cuarto lugar, se observa que las organizaciones campesinas colombianas reaccionan en escenarios políticos globalizados y coyunturas nacionales particulares, respondiendo a unas trayectorias de lucha 
que configuran históricamente el sentido de la movilización. Fensuagro y el CNA llevan a cabo un proceso de enmarcamiento global (Tarrow, 2007) con LVC que se materializa en la forma en que se comprenden los procesos, se identifica lo campesino y se actúa para posicionar las demandas y dar fuerza local, nacional y global a la movilización.

En quinto lugar, es posible hablar de un marco de acción colectiva global en LVC que permite construir distintos puentes entre la diversidad de problemas locales que pueden enfrentar las organizaciones locales ante las políticas neoliberales y las injusticias de cada contexto bajo unos antagonismos claros. Además, agrega identidades campesinas ligadas a la relación con la tierra lo suficientemente cohesionadoras, pero al mismo tiempo flexibles, para dar cabida a campesinos y campesinas de todo el mundo y proponer repertorios de acción comunes que se nutran y sumen a las experiencias de cada contexto. El campesinado colombiano ha estado en estas luchas y globales, dándoles mayores perspectivas en la manera en que se identifican, se organizan, y actúan.

Finalmente, este trabajo constituye un aporte fundamental a la comprensión de las nuevas dinámicas de acción colectiva y de resistencia al neoliberalismo por parte del campesinado colombiano. Estos procesos que, sin perder de vista las particularidades colombianas, merecen ser puestos en diálogo con perspectivas globales para ampliar tanto las lecturas como las soluciones. Una vez que se mire desde otro nivel - como el mismo campesinado ha comenzado a hacerlo-, se aportará bastante a la manera en la que la academia ve y se relaciona con el campesinado.

\section{Referencias}

Agencia Prensa Rural, Prensarural. (2008). Se devela la estrategia paramilitar del ejército en Viotá (Cundinamarca). Recuperado de https://prensarural.org/spip/spip.php?article1326

Agencia Prensa Rural, Prensarural. (2009). Qué es y por qué lucha Fensuagro. Recuperado de http://prensarural.org/spip/spip. php?article2111

Andretta, M., Della Porta, D., Reiter, H., y Mosca, L. (Eds.). (2006). Globalization from Below. Transnational Activists and Protest Networks. Minneapolis: Minnesota University Press. 
Appadurai, A. (2001). Grassroots globalization and research imagination. En A. Appadurai (Ed.), Globalization (pp. 1-21). Durham: Duke University Press.

Asociación Campesina del Valle del Río Cimitarra, ACVC. (enero, 2001). El neoliberalismo, la cuestión agraria y el conflicto social y armado en Colombia. Ponencia presentada en la Conferencia Internacional “El otro Davos". Valle del Río Cimitarra, Magdalena Medio, Colombia. Recuperado de https:// www.prensarural.org/acvc/acvc20010119.htm

Benford, R. y Snow, D. (2000). Framing processes and social movements: An overview and assessment. Annual Review of Sociology, 26(1), 611-639. https://doi.org/10.1146/annurev. soc.26.1.611

Berry, A. (2002). ¿Colombia encontró por fin una reforma agraria que funcione? Revista de Economía Institucional, 4(6), 24-70. Recuperado de https://revistas.uexternado.edu.co/index.php/ ecoins/article/view/240

Braga, F. (2012). Lutas camponesas na escala internacional: um estudo sobre a Via Campesina. Revista NERA, 15(20), 58-82. https:// doi.org/10.47946/rnera.v0i20.1865

Brown, W. (2005). Neoliberalism and the End of Liberal Democracy. Edgework. En Critical essays on knowledge and politics (pp. 37-59). Princeton: Princeton University Press.

Cepeda Másmela, C. (2019). Coca y desempleo. Resistencias contra el neoliberalismo entre lo local y lo global. Bogotá: Editorial Javeriana.

Cepeda-Ladino, J. C. (2013). Una aproximación histórica al municipio de Viotá, Cundinamarca. Sub-Proyecto "Tejido Social". Bogotá: Grupo de Estudios Regionales Latinoamericanos-GERL de la Universidad Piloto de Colombia. Recuperado de www. researchgate.net/publication/316911802_Una_aproximacion_historica_al_municipio_de_Viota_Cundinamarca

Coordinador Nacional Agrario, CNA (2009). Plataforma Política Coordinador Nacional Agrario CNA. Colombia. Recuperado de http://cedins.org/index.php/materiales-pdf/ doc_download/50-plataforma-politica-coordinador-nacional-agrario-c-n-a-colombia

Corrales, E. y Forero, J. (octubre, 1992). La economía campesina y la sociedad rural en el modelo neoliberal de desarrollo. Ponencia 
presentada en el Segundo Congreso de Investigación de la Pontificia Universidad Javeriana. Bogotá, Colombia.

Cox, R. (1981). Fuerzas sociales, Estados y órdenes mundiales: más allá de la teoría de las relaciones internacionales. Relaciones Internacionales, 24, 99-116. Recuperado de https://revistas.uam. es/index.php/relacionesinternacionales/article/view/5195

Cox, R. (1986). Social forces, states and world orders: Beyond International Relations Theory. En R. Keohane (Ed.), Neorealism and its Critics (pp. 204-254). Nueva York: Columbia University Press.

Della Porta, D. y Tarrow, S. (2005). Transnational processes and social activism: An introduction. En D. Della Porta y S. Tarrow (Eds.), Transnational protest and global activism (pp. 1-17). Lanham: Rowman and Littlefield.

Desarmais, A. (2007). Globalization and the power of peasants: La Via Campesina. London: Pluto Press.

Escobar, A. (2012). Una minga para el posdesarrollo: lugar, medio ambiente y movimientos sociales en las transformaciones globales. Bogotá: Ediciones Desde Abajo.

Federación Nacional Sindical Unitaria Agropecuaria, Fensuagro. (2017). Instituto Agroecológico Latinoamericano María Cano. IALA Colombia. Recuperado de http://www.fensuagro.org/index.php/iala-colombia/1027-instituto-agroecologico-latinoamericano-maria-cano

Fensuagro (2009). Qué es y por qué lucha Fensuagro. Agencia de Prensa Rural. Recuperado de: http://prensarural.org/spip/spip. php?article2111

Gilhodes, Pierres. (1988). Las Luchas Agrarias En Colombia. Medellín: La Carreta.

Gill, S. (2008). Power and resistance in the new world order. Nueva York: Palgrave McMillan.

Gill, S. (2012). Introduction: Global Crises and the Crisis of Global Leadership. In S. Gill (Ed.), Global Crises and the Crisis of Global Leadership (pp. 1-20).

Gramsci, A. (1973). Selection from the Prision Notebooks. London: Lowerence and Wishart.

Kaur, J. (2017). Reclaiming the food system: Agroecological pedagogy and the IALA María Cano. Alternautas: (Re)searching de- 
velopment. Recuperado de http://www.alternautas.net/ blog/2017/8/17/reclaiming-the-food-system-agroecological-pedagogy-and-the-iala-mara-cano

Keck, M., y Sikkink, K. (2000). Activistas Sin Fronteras. México, D.F: Siglo XXI.

Legrand, K. (1986). Los antecedentes agrarios de la violencia: El conflicto social en la frontera colombiana, 1850-1936. En G. Sánchez y R. Peñaranda (Comps.), Pasado y presente de la violencia en Colombia (pp. 119-137). Bogotá: La Carreta Editores.

La Vía Campesina, LVC. (2017). ¡Globalicemos la lucha, globalicemos la esperanza!: Presentación. La Vía Campesina: Documentos Claves. Recuperado de https://viacampesina.org/es/ wp-content/uploads/sites/3/2017/07/La-Via-CampesinaTrifold-Brochure-l-ES-l-Print-ready-min.pdf

La Vía Campesina, LVC. (2018). Movimiento Campesino Internacional. Recuperado de https://viacampesina.org/es/

Martínez-Torres, M. E. y Rosset, P. M. (2014). Diálogo de saberes in La Vía Campesina: food sovereignty and agroecology. Journal of Peasant Studies, 41(6), 1-19. http://doi.org/10.1080/0306615 0.2013 .872632

Melo, D. (2016). Una lectura al modelo de desarrollo rural colombiano. Revista Políticas Sociales Sectoriales, 2(2), 821-835. Recuperado de http://www.ts.ucr.ac.cr/binarios/pela/pl000621.pdf

Melucci, A. (1994). Asumir un compromiso: identidad y movilización en los movimientos. Zona Abierta, 69, 153-179.

Menser, M. (2008). Transnational participatory democracy in action: The case of La Via Campesina. Journal of Social Philosophy, 39(1), 20-41.

Molano, A. (2015). La noche del campesino. Recuperado de https:// www.elespectador.com/opinion/la-noche-del-campesinocolumna-565015/

Moore, J. W. (2017). The Capitalocene, Par I: On the Nature and Origins of our Ecological Crisis. The Journal of Peasant Studies, 44(3), 594-630. https://doi.org/10.1080/03066150.2016.1235036

Moore, J. W. (2018). The Capitalocene, Part II: Accumulation by Appropriation and the Centrality of Unpaid Work/Energy. The Jour- 
nal of Peasant Studies, 45(2), 237-279. https://doi.org/10.108 $0 / 03066150.2016 .1272587$

Reitan, R. (2007). Global activism. Nueva York: Routledge.

Rosset, P. y Martínez, M. (2016). Agroecología, territorio, recampesinización y movimientos sociales. Estudios Sociales. Revista de investigación científica, 25(47), 275-299.

Sklair, L. (2003). Sociología del sistema global. Barcelona: Gedisa.

Tarrow, S. (1994). El poder en movimiento. Madrid: Alianza Editorial.

Tarrow, S. (2007). The new transnational activism. Cambridge: Cambridge University Press.

Tilly, C. (2010). Los Movimientos Sociales, 1768-2008. Desde Sus Orígenes a Facebook. Barcelona: Crítica.

Tobasura, I. (2009). De campesinos a empresarios. La retórica neoliberal de la política agraria en Colombia. Revista NERA, 12(15), 7-21.

Tovar Pinzon, H. (1975). El Movimiento Campesino En Colombia Durante Los Siglos XIX y XX. Bogotá: Ediciones Libres.

Worth, O. (2013). Resistance in the Age of Austerity. London: Zeld. 